\title{
Evaluation of the Determinants of Smallholder Famers' Participation in Agricultural Extension in Western Ethiopia
}

\author{
Firdisa Birru Goshu \\ Department of Economics, Wollega University, Nekemte, Ethiopia \\ Email address: \\ Firdisabirru.goshu@yahoo.com, firdisab@wollegauniversity.edu.et \\ To cite this article: \\ Firdisa Birru Goshu. Evaluation of the Determinants of Smallholder Famers' Participation in Agricultural Extension in Western Ethiopia. \\ International Journal of Agricultural Economics. Vol. 4, No. 2, 2019, pp. 48-54. doi: 10.11648/j.ijae.20190402.12
}

Received: January 31, 2019; Accepted: March 6, 2019; Published: March 27, 2019

\begin{abstract}
The study brought new estimates of determinants of smallholder farmers' decision to participate in agricultural extension service in Western Ethiopia using 2017/18 farm household survey data. Multi-stage proportionate random sampling technique wasused to collect farm data of 360 households of which 245 farm households are participants and the remaining 115 farm households are non-participants in extension service. Both quantitative and qualitative research method was used and Primary data was obtained using structured questionnaires. Secondary data was also collected from reports, journals, past research works, official documents and the internet. The result of maximum likelihood estimation showed that sex of household, education level of household, family size, age of household, experience in extension, farming experience, farmers' access to social network and DAs' frequency of visitwere found to be significant determinants for the household participation in agricultural extension services. The conclusion is that the local and regional government should focus and invests massively in supply of extension services to smallholder farmers in order to promote crop production and food consumption.
\end{abstract}

Keywords: Agricultural Extension, Participation, Logistic Regressions, Descriptive, Productivity

\section{Introduction}

With encouraging environment, extension services can improve agricultural Productivity through providing farmers with information that helps them to optimize use of limited resources. Ethiopia's extension system has great potential to help farmers throughout the country. With approximately 21 development agents (DAs) per 10,000 farmers, and even more in the high-potential areas, Ethiopia has one of the densest agricultural extension systems in the world. In Ethiopia, Agricultural Development Programs (ADP) plays the function of extension and input delivery services in the agricultural sector. [1-3] despite agriculture accounting for $90 \%$ of the country's exports and employment opportunities, the sector did not receive the attention it deserved until the third five-year development plan from 1967 to 1973 . The problems that emanate from agriculture at grass roots level are identified by Extension Personnel and related to the researchers for plausible solutions [4-5]. The researchers then provide information through recommendationsthe leaders who distribute improved technologies [6].

Ethiopian current development strategy is one mechanism of poverty reduction which includes the Sustainable Development and Poverty Reduction Program (SDPRP) approved in 2002 and 2004. To implement these strategies acess to extension services are vital actors that, the government has assigned agricultural development agents having the responsibility of improving small holder productivity and promoting small holder commercialization. The Ethiopian government adopted Agricultural Development Led Industrialization (ADLI) and private sector development strategy in 1995. An element of these strategies was focused on agricultural extension services development for creation of productive job opportunities, adoption of new and appropriate technologies, and enhancement of the development of the country's dominant sector which have wide-ranging backward and forward linkages with other sectors.

Farmer's participation in extension services has been increasing from time to time in several developing economies. Various studies conducted in different countries on the 
assessment of agricultural etension services attest to this fact. [7] The study had found that extension is responsible for serving about one billion small-scale farmers in the world and the improvement of agricultural sciences and technology has brought about dramatic changes in the agricultural sector. The responsibility of extension is to empower farmers and enable them to identify and analyze their agricultural problems so they areable to make correctdecisions [8-9]. Studies have shownthat the efficiency of agricultural extension activities depends substantially on the attributes of farmers receiving the information.

Agriculture is the dominant sector of the Ethiopian economy and therefore this particular sector determines the developmentand growth of all the other sectors and, consequently, the wholenational economy. An estimated 85 percent of the population is engaged in agricultural production. Agriculture accounts for half of GDP, $83.9 \%$ of exports, and $80 \%$ of total employment. Over $50 \%$ of all smallholder farmers operate on one hectare or less. Smallholder producers, whichare about 12 million households, account for about 95\% of agricultural GDP. Agricultural production is mainly subsistence, and a large portion of the country'scommodity exports is provided by the small agricultural cash-crop sector. The country is mainly characterized by low output rain-fed mixed farming with traditionaltechnologies. The sector has remained more or less static forcenturies. People have remained poor. There were different but interwoven constraints. The presence of an unproductive class, lack of capital, poor infrastructure, absence ofaccess to markets, a shortage of skilled manpower, land degradation, populationpressure, religion, culture, deforestation, tenure regimes and polices, poor landmanagement practices and varied but interrelated natural factors could be mentionedas important factors of rural poverty.

The overall objective of the study is to elicit determinants of smallholder farmers' decision to participate in agricultural extension and its extent on, Bako district, Bako and Lega Kella branches. The specific objectives are:

1. Assess the level of awareness of farmers on the significance of extension services to their livelihoods.'

2. Identify and analyze the factors (household and institutional) that determine farmers' participation decision in agricultural extension services.

3. Evaluate rural farmers' satisfaction with the provision of the agricultural extension service in Jima Ganati District.

\section{Working Hypothesis}

Farmers in the rural parts of Ethiopia are characterized by heterogeneity in various aspects of livelihoods like differences in resource endowments, knowledge of farming practices, ability of scarce resource utilization and their management and other socio-economic factors which could lead to differences in their participation in agricultural extension services. The following hypothesis can be tested using the Likelihood ratiotest: $L R(\lambda)=2(\mathrm{ULLF}-\mathrm{RLLF})$, Where, ULLF and RLLF are the values of unrestricted loglikelihood function under $\mathrm{H} 1$ and that of the restricted loglikelihood function under Ho, respectively [10]. The null hypothesis is rejected if the calculated chi-square is over than the critical chi-square with degrees of freedom equal to the number of restrictions at null hypothesis at $1 \%, 10 \%$ or $5 \%$ level of significance i.e. $\mathrm{LR}>\chi \mathrm{c}^{2}$ [11]. If the sample size is large the test statistic $\lambda$ follows the chi-square $(\chi 2)$ distribution with degrees of freedom equal to the number of restrictions imposed by the null hypothesis.

We can formulate the following null hypotheses:

1) The hypothesis that chooses the appropriate functional form for binary logit model that canadequately represent the data was tested. In fact the choice of functional form has insignificant effect on the overall results and limited effect onempirical efficiency measurement in particular [12].

$\mathrm{H}_{0}: \beta_{1}=\beta_{2}=\ldots .=\beta_{14}=0$. The coefficients of the predictor variables are simultaneously zero against $\mathrm{H} 1$ : the above coefficients of explanatory variables in binary logit modelare statistically significantly different from zero meaning that the explanatory variables are important in the model.

2) The hypothesis that Participation in agricultural extension and family size are unrelated was tested. $\mathrm{H}_{0}: \beta_{2}=0$ against $\mathrm{H}_{1}: \beta_{2} \neq 0$.

3) The hypothesis that Participation in agricultural extension and age and agesquare were not related tested. $\mathrm{H}_{0}: \beta_{3}=\beta_{4}=0$ against $\mathrm{H}_{1}: \beta_{3}=\beta_{4} \neq 0$.

4) The hypothesis that Participation in agricultural extension does not vary interms of access to transport tested. $\mathrm{H}_{0}: \beta_{5}=0$ against $\mathrm{H}_{1}: \beta_{4} \neq 0$.

5) Participation in agricultural extension does not vary with farm size and farming experience.

\section{Related Literature}

Agricultural extension refers to the exchange of knowledge with the aim of helping rural families to develop skills needed to solve their immediate problems and improve their lives [13] Tanzania extension agent: a professional employee of the ministry of agricultural food security and cooperative including ward-, village-, and district-based staff. Extension delivery methods: techniques used by extension agents in teaching the target group; can be classified by contact as individual, group, and mass methods [14]. Community-Based Organizations and other similar agencies need to make concerted efforts to sensitize skeptical farmers to benefit from the services they offer. Encouraging partnerships with local farmer organizations would increase awareness and is also likely to improve the perceptions that some farmers hold regarding these agencies by actively including them in their activities. Another important finding suggests that males were significantly more likely to seek extension advice or to be visited by agents. This reveals the critical need to gender-sensitize extension providers and to create programs that specifically empowers female farmers to 
proactively seek all available resources of information pertinent to improving their farm productivity and management systems.

\section{Materials and Methods}

To assess the determinants of smallholder farmers' decision to participate in agricultural extension services the data was largely based on the primary data, information collected from the 360 sample farmers and 10 key informants. Also different literatures via books, journals and articles were important sources of secondary data. Both descriptive statistics and binary logit model wereemployedto analyze the data. Both close ended and open ended questions were used to collect data from 185 farmers of four Kebeles. The sampling design that was applied for the research is simple random sampling. There are total of 3600 households in the four kebeles. The 3600 households in the Kebeles were considered as the target population. Using Miller and Brewer (2003) formula for sample size computation:

$n=\frac{N}{\left[1+N\left(\delta^{2}\right)\right]}$ Where $\mathrm{n}=$ Sample size; $\mathrm{N}=$ Total household; $\delta=$ precision level. Accordingly, the researcher assumed a precision level $(\delta)$ of $5 \%$. Given the total households of 3600 in four Kebeles, the sample size was;

$$
n=\frac{3600}{\left[1+3600\left(0.05^{2}\right)\right]}=\frac{3600}{[10]}=360
$$

Where $n=360$ is the total sample farm households were selected for the study.

\subsection{Description of the Study Area}

JimmaGeneti is one of the 10 Districts found in HoroGuduruWollega Zone and is located to the southern part of the zone, at $27 \mathrm{~km}$ to the south of Shambu town, capital city of the zone and $314 \mathrm{~km}$ from Addis Ababa, capital city of the country. It is sub-divided in to 12 farmer associations and 2 towns for its administrative purpose. The Geographically the district is bordered by; In the south by East wollega Zone, In south west by East Wolega Zone, In the West by Horo district, In the North west by Horo and In the east by Guduru district. In the east south by Jimma Rare district.

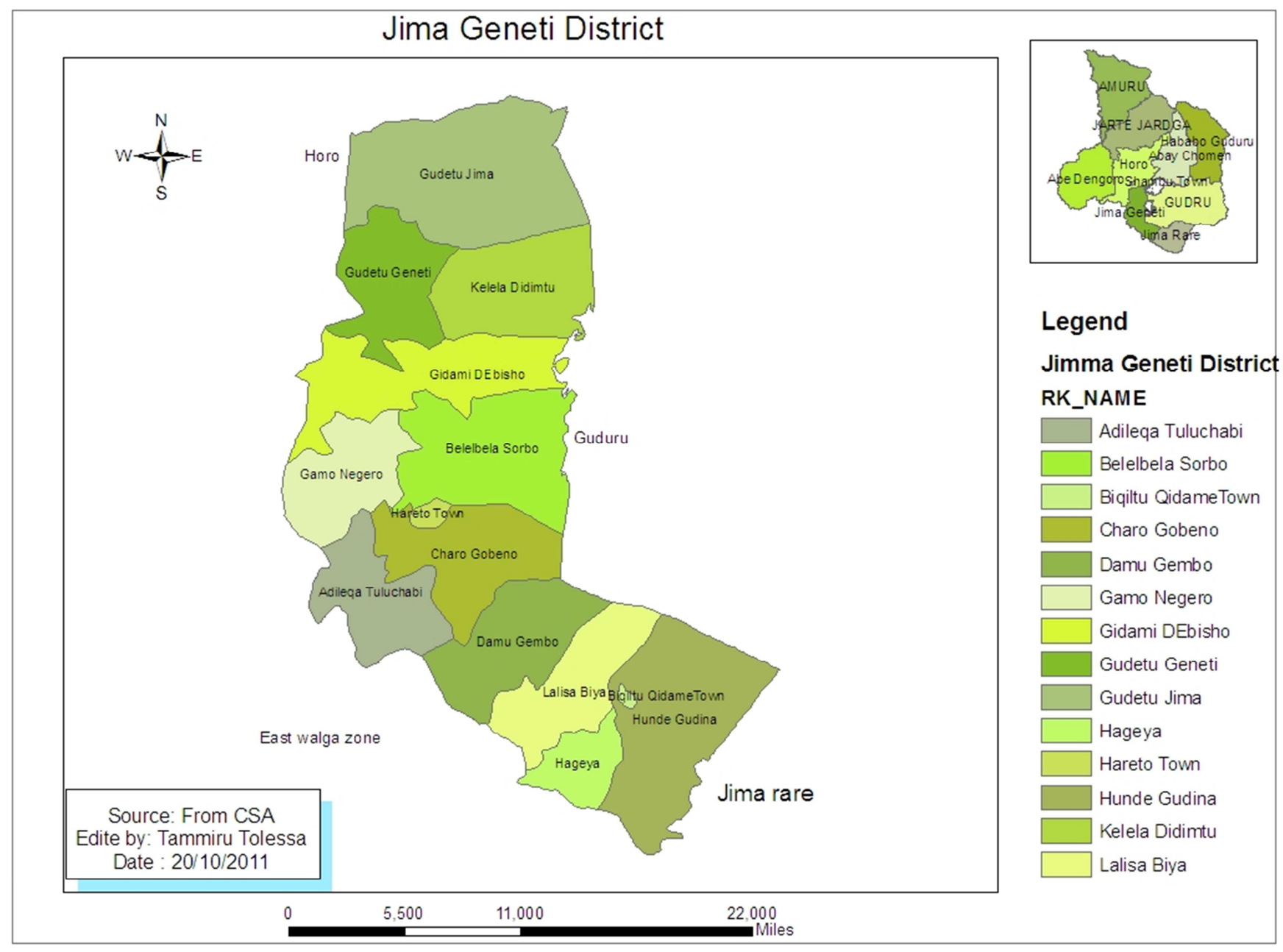

Figure 1. Map of Jima Geneti District.

The altitude range of the district is from $1900 \mathrm{~m}$ to $3000 \mathrm{~m}$ above sea level. The District is situated at an altitude $1900 \mathrm{~m}$ above sea level and the dominant climatic condition is subtropical climate type. The mean annual rain fall of the 
District is about $1600 \mathrm{~mm}-2000 \mathrm{~mm}$ and has a mean annual temperature between $15^{\circ} \mathrm{C}$ and $20^{\circ} \mathrm{C}$ (degree Celsius). Estimated total population in 2016 is 91,078 projected based on 2015 census. From this about 80,331 of the district's population are settled in rural and only 10,747 live in urban areas [15].

\subsection{Study Periodand Study Designs}

The study was conducted from June to August 20, 2018. A community based cross sectional study design was employed. Semi-structured interview and questionnaires were used to collect information in the area of socio-demographicand institutional factors.

\subsection{Source of Population}

All smallholder farmers sampled using simple random sampling method in Jima Ganatiboth participants and pnonparticipants.

\subsection{Method of Data Analysis}

Raw data was cleaned, coded and entered into the computer using Stata Software. Both descriptive statistics and binary logit model were used to investigate the relationship between the decision of the farmer to participate and the explanatorory variables. Derivation of the binary logit model begins from the linear probability model of the form:

$$
\begin{gathered}
P(y=1 / x)=\mathrm{Zi}=\beta_{0}+\beta_{1} x_{1}+\beta_{2} x_{2}+---+\beta_{k} x_{k} \\
P i=\frac{e^{z i}}{1+e^{z i}} \\
\mathrm{Zi}=\beta_{0}+\beta_{1} x_{1}+\beta_{2} x_{2}+---+\beta_{k} x_{k}+U i
\end{gathered}
$$

Where, $\mathrm{Pi}$ is the probability that the $i^{\text {th }}$ farmer participatingcultural extension, $z_{i}$-is a linear function of $n$ explanatory variables ( $\mathrm{x}$ ) and will be expressed as:

Where, $\beta$ o - intercept, $\beta i$ - regression coefficients to estimate, $\mathrm{U}_{\mathrm{i}}-$ is an error term.

$$
1-P i=\frac{1}{1+e^{z i}}
$$

Where $1-\mathrm{Pi}$ is the probability that a farmer will not participate in extension services.

$$
\left(\frac{\mathrm{Pi}}{1-\mathrm{Pi}}\right)=\left(1+\frac{\mathrm{e}^{\mathrm{zi}}}{1+\mathrm{e}^{-\mathrm{zi}}}\right)=\mathrm{e}^{\left(\beta_{0}+\beta_{1} x_{1}+\beta_{2} x_{2}+---+\beta_{k} x_{k}\right)}
$$

This is known as Odds ratio. Taking the natural logarithm of the Odds ratio, the logit model is:

$$
\left.\mathrm{Li}=\ln \left[\frac{\mathrm{Pi}}{1-\mathrm{Pi}}\right]=\ln \mathrm{e}^{\left(\beta_{0}+\beta_{1} x_{1}+\beta_{2} x_{2}+---+\beta_{k} x_{k}\right.}\right)=\beta_{0}+\beta_{1} x_{1}+\beta_{2} x_{2}+---+\beta_{k} x_{k}
$$

Where $\mathrm{x}_{1}, \mathrm{x}_{2}$, --------, $\mathrm{x}_{\mathrm{k}}$ are demographic, social, economic and institutional factors which will be included in the above econometric model.

\section{Results and Discussion}

\subsection{Descripitiveand Inferential Analysis}

The result of the survey indicated that out of the total sampled farmers68.5 and 31.5 percents participants and non participants are male and only about 61.7 and 38.3 percents participant and non participants are female respectively. Gender of farmers was hypothesized to be one of the variables that make a significant difference on the level of participation. The survey result showed significant difference $(\mathrm{t}=9.684)$ on agricultural extension service participation in terms of gender. Mean age of participants and non participants in agricultural extension services is 42.35 and 43.91, respectively.

The first hypothesis testing is that the coefficients on the agricultural extension service participation variables are simultaneously equal to zero, $\beta 1=\beta 2=\ldots \beta \mathrm{k}=0$. To test this hypothesis the log likelihood ratio is computed with the help of the loglikelihood function under the null hypothesis ( where all explanatory variables are simultaneously equal to zero) and a model under the alternate hypothesis (with all explanatory variables different from zero). The calculated value of LR equals to 189.25 while the critical value of LR, $\chi \mathrm{c}^{2}$, at 14 degrees of freedom with upper $1 \%, 5 \%$ and $10 \%$ significance levels, equals to $28.51,21.44$ and 15.45, respectively. Since, these critical LR values are much less than the computed LR valueat 14 degrees of freedom with upper $1 \%, 5 \%$ and $10 \%$ significance levels, the null hypothesis is highly rejected at all the above significance levels. Thus, the explanatory variables associated with the participation logit model are jointly significant and hence, they jointly explain participation variations among the farmers.

The second hypothesis is that the coefficients on the family size was equal to zero, $\beta 1==0$. To test this hypothesis the loglikelihood ratio is calculated with the help of the loglikelihood function under the null hypothesis and a model under the alternate hypothesis (with the coefficient of family size different from zero). The calculated value of $\mathrm{Lr}$ equals to 15.96 while the critical value of LR, $\chi c^{2}$, at 1 degree of freedom with upper 5\% significance level equals to 0.0039 . Since, this critical LR value is less than the computed LR ratio value at 1 degree of freedom with upper $5 \%$ significance level, the null hypothesis is rejected. The third hypothesis is that the test for the joint significance of age and 
agesquare in the logit model, i.e., whether age and agesquare are simultaneously equal to zero, $\beta 2=\beta 3=0$. To test this hypothesis the log likelihood ratio is calculated from the loglikelihood function under the null hypothesis (where age and agesquare are simultaneously equal to zero) and a model under the alternate hypothesis (both age and agesquare are different from zero). The calculated value of LR equals to 11.56 while the critical value of LR, $\chi c^{2}$, at 2 degrees of freedom with upper $10 \%$ significance level equals to 0.210 . Since, this critical LR ratio value is less than the computed LR ratio value at 2 degrees of freedom with upper $10 \%$ significance level the null hypothesis that age and agesquare are simultaneously equal to zero was rejected at $10 \%$ significance level with 2 degrees of freedom. These hypotheses test are summarized with the help of a table below.

Table 1. Summary results of LR test of hypotheses for the above results.

\begin{tabular}{lllll}
\hline Nullhypothesis & df & $\boldsymbol{\chi 2}_{\text {Cal }}$ & $\boldsymbol{\chi}_{\text {tab }}$ & Decisionrule \\
\hline$\beta_{1}=\beta_{2}=\ldots \beta_{14}=0$ & 14 & 189.25 & 21.44 & RejectHo \\
$\beta_{1}=0$ & 1 & 15.96 & 0.0039 & RejectHo \\
$\mathrm{B}_{2}=\beta_{3}=0$ & 2 & 11.56 & 0.210 & RejectHo \\
$\mathrm{B}_{4}=0$ & 1 & 8.698 & 4.60 & RejectHo \\
$\beta_{5}=0$ & 1 & 6.28 & 3.84 & RejectHo \\
$\mathrm{B}_{6}=0$ & 1 & 5.78 & 5.41 & RejectHo \\
\hline
\end{tabular}

Source:own computation from survey(2018).

\subsection{Empirical Results of the Binary Logit Estimation and Interpretation}

The dependent variable is a binary outcome which takes a value of one if the respondent is participating in agricultural extension services and zero otherwise. Therefore, binary logit model is used to identify potential determinants of the agricultural extension services. The likelihood ratio has a chisquare distribution and it is used for assessing the significance of logistic regression. The result is significant at less than one percent probability level revealing that there is association between dependent and independent variables. The model output revealed that age and awarenes were found significant at less than one percent probability level. Gender, income, education, relative advantage, trial ability and experience were found to be significant at 5 percent probability level.

Table 2. Estimates of Maximum-likelihood logit model.

\begin{tabular}{llll}
\hline Variables & Coefficients & Z-value $(\mathbf{P}>|\mathbf{z}|)$ & Marginaleffects(average $=\mathbf{X})$ \\
\hline Familysize & 0.68527 & $2.304^{* *}(0.035)$ & $0.123454(4.34)$ \\
Age & -0.4141572 & $-3.09^{* * *}(0.002)$ & $-0.1403316(43.09)$ \\
age2 & 0.2010688 & $2.07 *(0.039)$ & $0.02304139(1898.7)$ \\
Ext. exprience & 0.291133 & $-3.27^{* * *}(0.000)$ & $-0.0352884(10.72)$ \\
Transport access & 0.0958403 & $1.14(0.252)$ & $0.0371112(0.91)$ \\
farmexperience & 0.2230366 & $2.91 *(0.064)$ & $-0.0592587(2.42)$ \\
DAs visit (Per year) & 0.2050145 & $2.24 *(0.001)$ & $0.1941142(0.52)$ \\
Farmsz & 0.0126722 & $2.25(0.624)$ & $0.0349069(8.25)$ \\
DAs not polite & -2.328742 & $-0.13(0.137)$ & $0.2158608(0.75)$ \\
Sex of head & 2.2483041 & $1.89 *(0.035)$ & $0.0659371(0.44)$ \\
Education of head & 1.1702837 & $5.55^{* * *}(0.000)$ & $0.1659371(4.50)$ \\
social association & 0.3521624 & $1.65 *(0.099)$ & $0.136364(1.44)$ \\
Irrigation acess & -1.136445 & $-0.94(0.451)$ & $0.3625565(0.17)$ \\
tlu & 0.0560434 & $-1.00(0.924)$ & $0.0217011(3.65)$ \\
cons & 0.1987902 & $0.16(0.873)$ & \\
Restricted loglikelihood $=-321.2531$ Number of obs $=360$ & & \\
Unrestricted loglikelihood $=-218.2327$ LRchi2 $(14)=189.25$ & & \\
Prob $>$ chi ${ }^{2}=0.0000$ & & & \\
Marginal effects after logit: $\mathrm{y}=\operatorname{Pr}(\mathrm{y} 1)($ predict $)=0.72964712$ & & \\
\hline
\end{tabular}

Source:own computation from rural survey (2018)

$*$, **and ${ }^{* * *}$ shows significance at $10 \%, 5 \%$ and $1 \%$ significancelevels, respectively.

Nine of the fourteen explanatory variables havestatistically significanteffecton participation in agricultural extension service: these variables are family size, age of head, agesquare, farmer's experience in extension service, farming experience, development agentsfarmer's farm visit, education level of the household head, sex of household head, and farmers' access to social network. The coefficient on the number of members in a family is significant at 5\% level of significance with positive sign. This shows that a famer with large number of members has a greater probability of participating in extension services than a famer with less family size. Its marginal effect shows that one additional 
person to a family will increase the probability of the farmer's participation in agricultural extension by $12.34 \%$ marginal effect, holding other factors constant.

Binary logit output indicated that age and agesquare have negative and positive significant effect at $1 \%$ and $5 \%$ levels of significance on farmers' decision to participate in agricultural extension service, respectively. This may be because of the fact that older household heads might be conservative and might not trust the institutions as safe and might prefer traditional ways of farming. In addition to this, as the farmer gets older his managerial ability and physical capacity are expected to decrease. It sustains isolation because of lack of time or energy to attend meetings and hence, difficult to participate in extension services. But, to see the increasing effect of age increment (experience) on participation in extension service, agesquare was used by the researcher in logit model and has positive coefficient as prior expectation. The marginal effect showed that a marginal change in age from the average of 43 years is associated with a $14.03 \%$ decrease in marginal effect, ceteris paribus.

Binary logit estimation result indicated that Development Agents farm visit is seen to significantly affect the likelihood of participation in agricultural extension service. Frequency of DAs' farmers' farm visit has positive effect on the probability of participation in extension service of the respondents. The finding of Elias et al (2015) showed that frequency of the DAs contact with farmers is among the major factors positively determining households' satisfaction with the extension services. [16] Variables such as level of education, DAs' contact, and age of farmers were positively related to level of participation in agricultural extension services at $1 \%, 1 \%$, and $10 \%$ level of significance respectively.

Farmer's experience in extension services and years' of schooling are highly significant at $1 \%$ level with positive sign. Farming experience of the household head's is positively related with the participation in extension service. This shows that a more experienced farmer has more probability of participation in agricultural extension services. Sex of the household head was also found to be one of the other significant factor at 5\% significance level with a positive sign. The study showed that men household heads are more likely to participate in agricultural extension service than women counterparts. [17] The study found that social customs imposed the greatest barriers to achieving gender equity in extension service participation and provisions.

\section{Conclusion and Policy Implications}

The results of descriptive statistics show that the mean age of participants and non participants in agricultural extension services is 42.35 and 43.91 respectively. There is significant difference between male an female on decision to participate in agricultural extension. Therefore, this implies that DAs and local leaders as well as professional farmers could initiate and train female headed households so as to increase their partcipation in agricultural extension in the study area.
The results of t-test show that mean score of the participants and non participants interms of experience in farmingwas found as 8 and 5.45, respectively and significant at $5 \%$ level. Therefore, this implies they could promote experience sharing among farmers to increase the likelihood of their participation in extension services. The result of binary logit estimation showed that family size is significantly and positively affecting the likelihood of participation in extension services sot that due attention could be given to small family size households. Education, experience in extension services and social networkind are positively influencing the probability of smallholder farmers' participation decision in agricultural extension services. Thus, DAs and the local leaders should initiate the study area farmers to participate in education, social networking and experience sharing. Frequency of DAs' farmers' farm visit has positive effect on the probability of participation in extension service of the respondents. Therefore, the study recommended the DAs should increase their frequency of contact with farmers. In addition, the concerned local leaders should develop new pro-poor agriculturaldevelopment approaches and strengthening and initiating farmers in extension services in the study area.

\section{References}

[1] Abate, H. (2007). Review of extension systems applied in Ethiopia with special emphasis to the participatory demonstration and training extension system. Food and Agriculture Organization of the United Nations, (unpublished), Addis Ababa, Ethiopia.

[2] Anderson, J., Van Crowder (2000). The present and future of public sector extension in Africa. Contracting out orcontracting in? The Public Administration and Development 20: 373-384.

[3] Asfaw, S., Shiferaw, B., Simtowe, F., \& Lipper, L. (2012). Impact of modern agricultural technologies on smallholder welfare: Evidence from Tanzania and Ethiopia. Foodpolicy, 37, 283-295. http://dx.doi.org/10.1016/j.foodpol.2012.02.013.

[4] World Bank Group. (2016). Enabling the Business of Agriculture 2016: Comparing Regulatory Good Practices. Washington, DC, USA: World Bank Group.

[5] Ragasa C, Ulimwengu J, Badibanga T (2016). Factors Affecting Performance of Agricultural Extension: Evidence fromDemocratic Republic of Congo. J

[6] Yao Pan, Stephen C. Smith, Munshi Sulaiman (2015). Agricultural Extension and Technology Adoption for Food Security:Evidence from Uganda. IZA Discussion Paper No. 9206.

[7] Nagel, U.(1997). Improving agricultural extension: A reference manual. Rome, Italy: FAO.

[8] Davis K, Swanson B, Amudavi D et al. (2010). In - depth Assessment of the public agricultural extension system ofEthiopia and recommendations for improvement. IFPRI discussion paper 01041. Eastern and South Africa Regional Office. Addis Ababa, Ethiopia. 
[9] Berhanu A (2009). The Ethiopian extension and farmer: A view from the farm. In: Svein E, Aspen H, Teferra B, Bekele (eds.). Proceeding of the 16th International conference ofEthiopian studies, Trondheim, 2009.

[10] Gujarati, D. N. (1998). Essential of Econometrics, 2nd ed.

[11] Greene, H. (2000). Econometric Analysis, 4th ed. Prentice Hall International, Inc USA.

[12] Pan, Y., Smith, S. C., \& Sulaiman, M. (2015). Agricultural extension and technology adoption for foodsecurity: Evidence from Uganda (No. 9206). IZA Discussion Papers. Agric. Educ. Extension 22:113-143. DOI

10.1080/1389224X.2015.1026363.

[13] Berhanu K (2012) The political economy of agricultural extension in Ethiopia: Economic growth and political control. Working paper 042. UK Department for International Development (DfID). Future Agricultures.
[14] FAO (Food and Agriculture Organization of the United Nations). (2010). Ethiopia country brief. Retrieved from www.fao.org/countries/55528/en/eth/.

[15] Cetral Statistical Authority (2015). Ethiopian Population Survey.

[16] Dercon S, Gilligan DO, Hoddinott J, Woldehanna T (2009) The impact of agricultural extension and roads on poverty and consumption growth in fifteen Ethiopian villages. Am J Agr Econ 91 (4): 1007-21. DOI 10.1111/j.14678276.2009.01325.x.

[17] Ministry of Agriculture (MoA) (2010) Participatory Agricultural Extension System (Amharic version). MoA, Addis Ababa, Ethiopia. 